\title{
ALLIANCES BETWEEN COMPETITORS AND CONSUMER INFORMATION
}

\author{
Paolo G. Garella \\ University of Milano
}

\author{
Martin Peitz \\ International University in Germany and \\ University of Mannheim
}

\begin{abstract}
Alliances between competitors in which established firms provide access to proprietary resources - for example, their distribution channels - are important business practices. We analyze a market where an established firm, firm $A$, produces a product of well-known quality, and a firm with an unknown brand, firm $B$, has to choose to produce high or low quality. Firm $A$ observes firm $B$ 's quality choice but consumers do not. Hence, firm $B$ is subject to a moral hazard problem which can potentially be solved by firm $A$. Firm $A$ can accept or reject to form an alliance with firm $B$, which is observed by consumers. If an alliance is formed, firm $A$ implicitly certifies the rival's product. Consumers infer that firm $B$ is a competitor with high quality, because otherwise why would the established firm accept to form an alliance? The mechanism we discover allows for an economic interpretation of several types of business practices. (JEL: L15, L13, L24, L42, M21, M31, D43)
\end{abstract}

\section{Introduction}

Firms entering a market often face an information disadvantage against established rivals. This implies high costs and time needed to convey information to consumers about their products - in particular, their product quality. Because newcomers represent a threat to the profitability of established firms, it should be surprising that the latter provide any form of cooperation or entry assistance to the rivals. In particular, one would expect incumbents to avoid lending their reputation to newcomers by forming alliances with them. However, the business literature and the press provide extensive evidence that this is not the case. In particular, alliances between competitors are documented in the pharmaceutical

\footnotetext{
Acknowledgments: This paper substitutes an earlier paper circulated under the title "Exclusionary Practices as Information Revealing Strategies". We received helpful comments from three referees, the editor Xavier Vives, and various seminar and conference audiences. Paolo Garella gratefully acknowledges financing from University of Crete under a Marie Curie Transfer of Knowledge Fellowship (E.U. 6th Programme, MTKD-CT-014288). Martin Peitz gratefully acknowledges financial support by the Deutsche Forschungsgemeinschaft (Heisenberg fellowship).

E-mail addresses: Garella: paolo.garella@unimi.it, Peitz: Martin.Peitz@i-u.de
} 
and automobile industry. ${ }^{1}$ Another example concerns the telecommunications equipment industry. As has been reported by Carlin et al. (1994, p. 10) "a small telecommunications equipment supplier was willing to become a key supplier to a large leading switch manufacturer even though they competed in certain markets. The larger company, recognized as a global leader in new technology, enhanced the reputation of the smaller company." 2 This example suggests that competing firms enter into an alliance with the purpose that one firm rents the reputation from the other.

Although the explanations of cooperative practices between competitors can be multiple, we here focus on their implications for information transmission. We show that, because established firms share their reputation with high-quality newcomers, alliances may solve the asymmetric information problem faced by newcomers. ${ }^{3}$ We limit the scope of our analysis to strategies that the established firms can implement through (legal) arrangements with other parties. Our lead example is that of marketing alliances between competitors, where the established firm provides market access for the entrant's product. This may include access to the distribution network of the established firm or the provision of after-sales services by the established firm. The established firm may even sell the product under its own brand (or a co-branding strategy may be agreed upon). In this paper, we formalize the notion that an alliance between competitors may provide the means for an unknown brand to overcome its information disadvantage vis à vis the established firm. The key result is that the established firm has an incentive to accept an entrant if it is of high quality and to reject if it is of low quality.

More precisely, we consider a market environment in which the information that the established firm $A$ possesses about the unknown brand of firm $B$ is also relevant to consumers. In particular, we take product quality as the relevant variable: The quality of a firm's product is indeed often only imperfectly known to consumers. ${ }^{4}$ For instance, think of entrants as firms entering certain countries as in the previous examples. We may therefore refer to firm $B$ as the entrant, and to firm

1. The evidence concerning alliances between competitors is discussed in Section 4 . There we also present examples from those two industries.

2. The identity of the firms involved is confidential (Michael Dowling, personal communication, March 31, 2006).

3. Our analysis can be seen as a particular case of coopetition within an industry, for a management perspective on coopetition see Brandenburger and Nalebuff (1996). In our model coopetition takes the following form: An entrant's product is introduced into the market by the incumbent although it competes with the incumbent's product.

4. The assumption that an entrant's quality may not be known to consumers is not new (see Farrell 1986) and seems natural for many markets. The assumption that the incumbent is perfectly informed about the competitor's quality while consumers are not is certainly admissible for a wide range of cases. It is indeed true for many markets that the single consumer should afford a disproportionately high cost to gain information about the entrant; these costs may be relatively low for firms in the business, thanks to their scale, their knowledge of the technology, or to the network of experts to which they have access. 
$A$ as the incumbent, without by this confining ourselves to the framework of an entry model. Firm $B$ is assumed to be subject to moral hazard because it chooses its product quality without the consumers observing it. Clearly, a firm with an unknown brand may be able to transmit credible information independently, thus revealing its quality or reliability. To do so, it must pay a cost, either through costly certification, or through other costly actions such as warranties or advertising-in the remainder we refer this cost as the certification cost. The two features, that revelation is possible for a high-quality firm $B$, and that it is necessarily costly, are both essential to our arguments. First, given entry, revelation must be affordable. Otherwise, the moral hazard problem would definitely trap firm $B$. Indeed, firm $A$ would always exclude a high-quality firm $B$, and given entry, firm $B$ would always choose low quality. Secondly, revelation (that is, certification) by firm $B$ must be costly. If it were not, the moral hazard problem would be trivially solved through certification and firm $B$ could always produce high quality when this is profitable. With costly revelation, furthermore, the costs may make it impossible to make positive profit with a certified high quality, to the effect that firm $B$ has to stay out.

Now, suppose that a high-quality firm $B$, after having sunk its entry costs, can make positive profits (net of certification costs). Then for the established firm the "reject" strategy against a high-quality rival has no foreclosing power, because the latter will be able to resist through certification and survive competition, that is a high-quality firm $B$ would certify if rejected. By contrast, a low-quality firm $B$ can never certify to be high quality. Therefore, firm $A$ 's best response to firm $B$ 's action to enter with high quality is "accept" (if it receives a payment from firm $B$ ). But then the reaction by firm $A$ represents good news to consumers about the quality of firm $B$ : By the self-interested act of not fighting, firm $A$ will signal the good quality of firm $B$. The resulting equilibrium outcome is very different from the outcome if alliances are forbidden. In this situation, firm $B$ never enters with high quality and may even stay out of the market. By contrast, as previously argued, staying in the market and producing high quality is a profitable strategy for firm $B$ if alliances are allowed.

Our result relies on the incentives of firm $A$ to respond differently to high than to low quality because it achieves a competitive advantage when unmasking a competitor to be of low quality. In this paper we formalize this competition story, which is novel and relies critically on the fact that incumbent and entrant are competitors in the market. In this setup, accepting to form an alliance can reveal information although the incumbent's reputation is immune to its actions. Hence, we consider a market in which the quality of firm $A$ is known with certainty and cannot be subject to downgrading. We do not model how an incumbent firm builds up reputation and simply assume that it has perfectly revealed quality (e.g., by certifying it). Still, firm $A$ is not indifferent to the rival's reputation because a higher reputation of the rival reduces firm $A$ 's market power. 
An alternative mechanism is that the established firm's reputation may suffer when selling jointly with an entrant of low quality-we call this the reputation story. As to the reputation story, that a firm's reputation may suffer, it has been noted that the possibility to exclude competitors from a distribution channel provides a mean to protect the manufacturer's brand image or quality recognition from free-riding by other firms (see Bork 1978). ${ }^{5}$ This kind of argument could be extended by stating that a refusal to associate the well-known firm's brand image to that of a competitor is a way to protect the value of past investments in reputation. Although related to our ideas, this argument does not apply to our model. ${ }^{6}$ The reputation mechanism is certainly of interest, but it is perhaps not so surprising, given the insights in the literature. Furthermore, a mechanism which does not rely on the incumbent's reputation being at stake provides a strong justification for the role of alliances to transmit information. From an antitrust perspective alliances between competitors are often regarded with suspicion. Therefore, an analysis of their competitive effects seems to be of particular importance.

Close to the present paper is our earlier work, Garella and Peitz (2000), about the signaling role of shared intermediation in a specific retailing environment. In that paper, we have analyzed a symmetric duopoly environment without entry decisions (ignoring the issue of the legality status of alliances), where shared retailing channels merely replace costly certification as a was to convey information to consumers. In the present paper we explore asymmetric environments: An established firm is an external provider of information to consumers about the quality of a rival. Here, the legality of certain actions is shown to have consequences on the amount of information conveyed to consumers and on the degree of competitiveness of the market. Therefore, the results in the present paper are much stronger than in our earlier paper: We show that the formation of alliances affects entry decisions and the decision which quality to provide. ${ }^{7}$

In Section 2, we present the model with potential entry and show the main results under moral hazard. We find that alliances between competitors can lead to entry with high quality, which would not occur if such alliances were not allowed. ${ }^{8}$ In Section 3 we sketch some extensions. We show that our results hold as well

5. This idea has been discussed in various places in the antitrust literature (e.g., Ornstein 1989).

6. Related to the reputation story, some recent work studies the possibility of brand signaling in the case of vertically related firms (see Chu and Chu 1994; Biglaiser and Friedman 1994, 1999). Similar to the signaling mechanism presented there, one could make the argument that an incumbent lends its reputation to another high-quality firm. Signaling by the incumbent firm then works because consumers are able to evaluate its reputation loss that it would incur in case of cheating.

7. Also, our current results carry over to adverse selection environments (see the Discussion section), whereas the results obtained in Garella and Peitz (2000) do not hold in such environments.

8. We also present equilibrium selection arguments invoking stability, as defined by Kohlberg and Mertens (1986), to give the unique prediction that alliances are a signal of the entrant's product quality. 
under adverse selection, where exclusion is enforced if Nature has selected the bad quality product for the entrant. We also argue that in an extended model with moral hazard and adverse selection the incumbent rejects to form an alliance with positive probability along the equilibrium path. In Section 4, we provide some examples and empirical evidence on alliances between competitors. We also discuss the usefulness of the results for the interpretation of other practices such as the use of common retail services (and in particular the allocation of physical space in superstores or shopping malls), white labels, licensing standards, and exclusionary practices, including membership refusal by professional associations. Section 5 concludes. The Appendix provides details on the existence and nature of mixed strategy equilibria and contains the proof of the proposition on equilibrium selection.

\section{Formal Analysis}

\subsection{A Moral Hazard Problem}

Two competing firms $A$ and $B$ share firm $A$ 's distribution (or promotion) channel if they form an alliance. Otherwise, firm $B$ has to build up its own channel. To focus on the asymmetric information aspect, suppose that firm $B$ does not have a cost disadvantage in building its own distribution channel. However, consumers observe whether firm $B$ sells through firm $A$ 's or its own distribution channel. For its services firm $A$ receives a fixed net payment of $f .{ }^{9}$ Without affecting the formal analysis, firm $A$ alternatively provides after-sales services to customers of firm $B$ and this is recognized by all consumers before purchase or, as another alternative, the product of firm $B$ is sold under the brand name of firm $A$.

We analyze a game played by the incumbent firm $A$, the entrant firm $B$, and by consumers. ${ }^{10}$ Firms may or may not be allowed to form an alliance. At stage 1 , firm $B$ has to pay an entry cost $e$ when choosing the product design. Alternatively, without any consequence upon the analysis, firm $B$ may be a firm that has already been active in the market and has to decide whether to exit the market or stay with high or low quality; ${ }^{11}$ if it exits at this point it avoids the fixed cost $e$. For

9. In several real-world examples we observe that the established firm does not receive a fixed payment but takes a share in the joint venture. This can be explained by a moral hazard problem within the joint venture where the established firm has to exert some effort which is non-contractible. However, in this paper we abstract from asymmetric information problems within an alliance and can therefore restrict the analysis to fixed payments.

10. To easily distinguish between the two firms, in this section we refer to the incumbent as "he" and the (potential) entrant as "she".

11. If this firm has to maintain its previous quality then consumers must not have learned the quality from past purchases. Alternatively, one can think of firm $B$ replacing an outdated product. 
simplicity, we assume that the sunk cost $e$ is independent of the product quality. Firm $A$ has already sunk this cost and is known to be of high quality. ${ }^{12}$

At stage 2, firm $B$ may ask to form an alliance with firm $A$, in which case firm $A$ can accept or reject. Firm $A$ receives a net payment of $f$. At stage 3, firm $B$ can certify high quality. We do not include the incentive problem of the certifying authority to tell the truth (see Biglaiser 1993) but simply assume that firm $B$ can reveal her high quality to consumers, albeit at a cost $g .{ }^{13}$ Firm $B$ can also exit the market at this point (it is never in the interest of firm $A$ to do so). Therefore, the interim participation constraint of firm $B$ must be satisfied at this stage. At stage 4 firms set prices and at stage 5 consumers form beliefs and make their purchasing decision. The game can be described as follows:

Stage 1: In-out decision and quality choice. The entrant decides whether to: a) pay the sunk cost $e$ and produce high quality, b) pay sunk the cost $e$ and produce low quality, or c) stay out of the market - thereby ending the game with zero payoff. The chosen quality $q_{B} \in\{H, L\}$ is common knowledge between incumbent and entrant but is not observed by consumers.

Stage 2: Distribution channel. Firm $B$ decides whether to ask to form an alliance, and then firm $A$ agrees or rejects the offer. If they form an alliance the incumbent receives a net payment of $f$.

Stage 3: Certification decision. Firm $B$ decides whether or not to certify her product quality and in case of certification she incurs costs $g$. She can also exit at this stage.

Stage 4: Price setting. Firms set prices (or quantities) for their products simultaneously. The cost difference between the production of high and low quality is denoted by $h$.

Stage 5: Consumer choice. Consumers observe the number of products, the prices of each product in the market, whether or not a distribution channel is shared, and any certification. They use this information to form their beliefs on the product quality of the entrant. Based on their beliefs they make their purchasing decision.

At a later point in the analysis, we will allow the entrant to randomize between qualities at stage 1 and the incumbent can reject the request to form an alliance with any probability at stage 2 . We do not formally introduce the possibility of random certification but our qualitative results will remain unaffected. Stage 4 is black-boxed in the profit functions because equilibrium prices depend only upon

12. If $e$ constitutes a fixed cost which has to be paid by firm $B$ when initially active, then also firm $A$ incurs this cost. Because firm $A$ is always active in our model, our analysis carries over to this alternative interpretation of $e$, provided that firm $A$ still makes positive net profits.

13. Certification can not only be interpreted as certification by an outside auditor (see Biglaiser 1993) but also as warranties provided by the entrant or the entrant's advertising. 
whether or not entry has occurred and upon the perceived quality of the entrant, see below. We characterize the perfect Bayesian equilibria (PBE) of this game.

If firm $B$ 's product is available on the market, consumers have to form beliefs based on the observation whether or not an alliance has been formed and whether or not firm $B$ has certified. Hence, consumers observe one of the following four situations: certification and alliance, denoted by $(C, 2)$, no certification and alliance, $(N, 2)$, certification and no alliance, $(C, 1)$, and no certification and no alliance, $(N, 1)$. For expositional convenience, suppose consumers believe that the brand is of high quality with probability 1 or 0 . Hence, beliefs of consumers are a map from $\{C, N\}$ times $\{1,2\}$ to $\{L, H\}$ and we write, for example, $b(C, 1)=H$ for the belief that firm $B$ produces high quality if she certifies and chooses separate retailing. Because only a high-quality firm possibly certifies, consumers have to believe that $b(C, 1)=b(C, 2)=H$. Beliefs $b(N, 1)$ and $b(N, 2)$ will be determined as part of the equilibrium analysis.

We analyze this setup under a number of assumptions (or properties) that profit functions have to satisfy. Note that, in general, the costs to provide a certain quality can be thought of as fixed or variable. To keep the analysis as simple as possible, we assume that product quality only affects the fixed costs of firm $B$ so that equilibrium prices only depend on perceived quality. ${ }^{14}$ This also implies that, because of the incentives to mimic, firms cannot use prices to signal firm $B$ 's product quality. ${ }^{15}$ Without loss of generality we set the fixed cost of low quality to 0 so that the cost difference between producing high and low quality, denoted by $h>0$, is the fixed cost of high quality.

The manufacturers' profits gross of fixed costs depend only on the perceived quality of the competitor, $q_{B}^{e}$, and we write $\pi_{A}\left(q_{B}^{e}\right)$ for the profits of the incumbent and $\pi_{B}\left(q_{B}^{e}\right)$ for the profits of the entrant. The latter can choose low or high quality, denoted by $L$ and $H$, respectively, or stay out of the market altogether. If the entrant does not enter the incumbent makes monopoly profits $\pi_{A}^{M}$ with $\pi_{A}^{M}>\pi_{A}\left(q_{B}^{e}\right)$ for any $q_{B}^{e}$.

Firms set prices (or quantities) noncooperatively. We do not impose a particular model of price or quantity competition, nor symmetry assumptions and only make assumptions on reduced profit functions:

$$
\begin{aligned}
\pi_{A}(L) & >\pi_{A}(H), \\
\pi_{B}(H) & >\pi_{B}(L) .
\end{aligned}
$$

14. The cost could also be modeled as a sunk cost which the entrant incurs when she chooses quality, which implies that firms do not have an incentive to downgrade high quality after entry because it does not give a cost advantage. This alternative specification, which we do not adopt, however, would lead to quality-dependent entry costs.

15. Price signaling is not possible in a one-shot oligopoly game in which quality differences only affect fixed but not variable costs and in which all consumers are uninformed. In our equilibrium qualities are separated through certification or alliance building. Because beliefs are constant in prices, firms set full-information prices. 
Assumption (A.1) states that the incumbent enjoys higher profits under full information when he competes against low quality. This means that he enjoys more market power competing against low quality. Assumption (A.2) states that under full information the entrant prefers to be of high quality, as a high-quality firm can extend her demand and increase price-cost margins. Assumptions (A.1) and (A.2) are met in many oligopoly models (Garella and Peitz (2000) provide several examples).

When deciding whether to enter at stage 1 , firm $B$ has to respect her participation constraints. Our next assumption states that under full information a high-quality entrant makes positive profits:

$$
\pi_{B}(H)-e>0 .
$$

This implies that under full information entry will always occur. Clearly, under Assumptions (A.1), (A.2), and (A.3), firm $B$ enters with high quality at stage 1 . At a subgame perfect equilibrium, profits are $\pi_{A}(H)$ and $\pi_{B}(H)-e$. Thus, in such a setup, alliances do not play a role under full information; therefore, any reason to form an alliance between competitors has been successfully excluded from our model, provided full information prevails.

We consider markets in which the cost of certification, $g$, is as high as to deny to firm $B$ the possibility to enter with certifies high quality and make positive profit:

$$
\pi_{B}(H)-e-g<0 \text {. }
$$

In other words, asymmetric information is a barrier to high-quality production because firm $B$ can only enter with low quality or stay out.

We first analyze the 5-stage game under the restriction that alliances between competitors are forbidden by law and punished by antitrust authorities. The analysis is then straightforward. Firm $B$ wants to be believed to be of high quality because in this case she gains $\pi_{B}(H)-e$ compared to $\pi_{B}(L)-e-h$. However, absent certification she has an incentive to cheat and therefore high quality is not sustainable. When certification is available, at stage 3 the high-quality entrant has the mean of perfectly revealing her quality, albeit at a cost. According to Assumption (A.4), the addition of this cost to the entry cost makes it unprofitable to enter the market.

Note that Assumptions (A.3) and (A.4) combined read as $0<\pi_{B}(H)-e<g$. If certification was cheap enough so that $\pi_{B}(H)-e-g \geq 0$, then the moral hazard problem could be directly solved by the entrant. However, if certification is costly so as to respect (A.4), then along the equilibrium path, the entrant will not enter with high quality. Beliefs then must satisfy $b(N, 1)=L$. It is straightforward to prove the following. 
PROPOSITION 1. Suppose alliances between competitors are not allowed. In any perfect Bayesian equilibrium, if $\pi_{B}(L)-e<0$ firm $B$ stays out of the market, whereas if $\pi_{B}(L)-e \geq 0$ she enters with low quality.

This proposition characterizes all PBE when alliances are not allowed. Information to consumers can be provided only directly by firm $B$, but certifying high quality leads to losses, when evaluated at stage 1 . Therefore, firm $B$ is trapped in the moral hazard impasse. There is no reason for the entrant to choose high quality.

\subsection{The Signaling Role of Alliances}

The present section shows how alliances between competitors may help to solve the moral hazard problem. This holds if profit functions satisfy a number of additional properties. First, consider the incumbent's profit. Note that the incumbent might be induced to indiscriminately accept a low as well as a high-quality entrant as a partner in alliance because he receives payment $f$. If that was the case, consumers would not observe any discrimination against a low-quality entrant and could not make any inference from the incumbent's action. Therefore, let us strengthen Assumption (A.1) to the following.

$$
\pi_{A}(L)>\pi_{A}(H)+f .
$$

This implies that the possible savings from sharing the fixed costs with the entrant are lower than the gains from unmasking that the latter is of low quality. For Assumption (A.1+) to be satisfied, both firms must be sufficiently close competitors.

Second, consider the incentive for a high-quality entrant to be revealed as such. We strengthen Assumption (A.2) to

$$
\pi_{B}(H)>\pi_{B}(L)+\max [0, g-h] .
$$

Under this assumption the entrant of high quality has an incentive to reveal her quality in spite of the certification costs. Allowing for meaningful certification means that Assumption (A.2+) has to be satisfied, because otherwise certification is never used by the entrant and the moral hazard problem would not be solved: The entrant either enters with low quality or not at all. Note that $g-h$ can be negative, in this case Assumption (A.2+) is equivalent to Assumption (A.2).

Third, we also strengthen Assumption (A.3) to cover the entrant's payment to firm $A$ in case of an alliance:

$$
\pi_{B}(H)-e-f>0 .
$$


Our last assumption concerns the credibility to use certification after a firm has entered with high quality. Although entry without an alliance is not profitable (see Assumption (A.4)) we assume that once the entry costs are sunk it is worthwhile for a high-quality entrant not to leave the market.

$$
\pi_{B}(H)-g>0 .
$$

Hence, the participation constraint of a high-quality firm $B$ is not binding in the subgame starting at stage 3 , independent of the previous action of firm $A$. If Assumption (A.5) did not hold, then firm $A$ would be enabled to reject an alliance with a type $H$ rival, induce exit, and remain a monopolist. Such rejection under the reverse of Assumption (A.5) is profitable as $\pi_{A}^{M}>\pi_{A}(H)+f$, which is implied by Assumption (A.1+).

In our model we have taken the payment $f$ to be exogenous. However, this may be considered as ad hoc because it is subject to negotiations between the two firms. Suppose the two firms engage in Nash bargaining at stage 3 so that each firm obtains half of the surplus that is generated by the alliance. This surplus is equal to $g$ so that the incumbent receives a payment of $f=g / 2$. Then if

$$
\pi_{B}(H)-e<g<\min \left\{\pi_{B}(H), 2\left(\pi_{B}(H)-e\right)\right\}
$$

holds, Assumptions (A.3+), (A.4), and (A.5) are satisfied. ${ }^{16}$

Consumer beliefs must take into account that exclusion is allowed. Here, we again focus on PBE with beliefs which attach either probability 0 or probability 1 to $H$. Recall that $b(C, \cdot)=H$, that is, independent of the retailing structure certification $C$ perfectly reveals high quality. It remains to specify beliefs for situations $(N, 1)$ and $(N, 2)$, where 1 stands for not forming an alliance and 2 for forming an alliance.

Note that any belief system containing the belief that separate retailing is associated with a high quality cannot be part of an equilibrium system of beliefs. Under such a belief system, indeed, firm $B$ would choose low quality at the first stage and enjoy the revenues of a high-quality firm so that the beliefs are not confirmed. It follows that all 0,1 -beliefs necessarily entail $b(N, 1)=L$. The complete belief system then is obtained by spelling out that either $b(N, 2)=L$ or $b(N, 2)=H$. Suppose that consumers form pessimistic beliefs, $b(N, 2)=L$ and consider the entrant's profit within an alliance. Under pessimistic beliefs and under the assumptions above, a high-quality entrant who does not certify obtains profits under separate retailing $\pi_{B}(H)-e-f-g$ if she certifies and $\pi_{B}(L)-e-f-h$ if she does not certify. When not forming an alliance we have the same expressions except that the entrant does not make the payment $f$.

16. Assuming that the entrant's operating profits (gross of certification costs and fixed payments) $\pi_{B}(H)$ are $(1+\lambda)$ times the entry cost, this inequality can be rewritten as $\lambda<g / e<\min \{1+\lambda, 2 \lambda\}$. 
Then, under this belief system, no saving on certification costs is possible and entry of high quality does not occur. If $\pi_{B}(L)-e<0$ this belief system sustains an equilibrium path at a PBE along which the incumbent remains a monopolist. Otherwise, she enters with low quality and does not request to form an alliance.

Alternatively, consumers may form optimistic beliefs, $b(N, 2)=H$. Under optimistic beliefs, an entrant who forms an alliance with the incumbent is believed to be of high quality and the moral hazard problem can be solved. The incumbent's threat to reject to form an alliance with the entrant convinces consumers of the entrant's high quality.

PROPOSITION 2. If alliances between competitors are allowed, there exists a PBE where the entrant chooses high quality, enters, and forms an alliance with the incumbent. This equilibrium entails the credible threat to reject to form an alliance with a low-quality entrant. If alliances were not allowed high quality could not be sustained in equilibrium.

Proof. Under optimistic beliefs, at stage 2, the entrant asks for an alliance because this is a dominant strategy, whether her true quality be $H$ or $L$. Indeed, if firm $A$ rejects, either type has a profit that is the same as when no alliance was proposed, but if firm $A$ accepts the profit will be higher for both types. For the low-quality entrant the perceived quality is $H$ instead of $L$. Rejection of high quality triggers certification by the entrant because by certifying she obtains $\pi_{B}(H)-g$ instead of $\pi(L)-h$ (see Assumption (A.5)). Hence, she saves $g-f$ if accepted. Rejecting the request to form an alliance only gives $\pi_{A}(H)$ to the incumbent. By contrast, if the incumbent accommodates the entrant and forms an alliance then he gets $\pi_{A}(H)+f>\pi_{A}(H)$. Then, to accommodate the entrant is the only strategy that can be part of a subgame perfect equilibrium in which the entrant chooses $H$, given optimistic beliefs.

Also, one can check that the incumbent's incentive constraint to reject access by a low-quality entrant is $\pi_{A}(H)+f<\pi_{A}(L)$, which coincides with Assumption $(\mathrm{A} .1+)$. Hence, out of the equilibrium path if the entrant is $L$, the incumbent has an incentive to reject the request to form an alliance. Accordingly, consumers' beliefs are confirmed at an equilibrium with optimistic beliefs and the entrant chooses $H$. The statement concerning the case that alliances are not allowed follows from Proposition 1.

The result implies that a prohibition of alliances between competitors under moral hazard can only prevent the attainment of socially desirable outcomes. ${ }^{17}$

17. Our result focuses on entry and the solution to the moral hazard problem. Denoting by $W^{M}$ social welfare under monopoly and by $W\left(q_{B}\right)$ welfare with entry of quality $q_{B}$, entry with high quality is unambiguously welfare-enhancing if $W(H)>W^{M}$ and $W(H)>W(L)$. When phrasing moral hazard as a problem from the social point of view, these inequalities are satisfied. 
To define bounds on entry costs such that the legality of alliances facilitates highquality entry, we define $e^{\prime} \equiv \pi_{B}(H)-g$ and $e^{\prime \prime} \equiv \pi_{B}(H)-f$. Recall that Assumptions (A.4) and (A.3+) imply $g>f$. Hence $e^{\prime}<e^{\prime \prime}$. An entry cost $e \in\left(e^{\prime}, e^{\prime \prime}\right]$ blocks high-quality entry if alliances between competitors are not allowed but entry with high quality takes place and the signaling mechanism works if they are allowed.

\subsection{Equilibrium Outcomes and Stability}

For a complete characterization of all PBE of the game, we have to introduce mixed strategies. We focus on the more interesting case where both $\pi_{B}(L)-e<0$ and $\pi_{B}(H)-e-g<0$, that is, on the case where neither a low nor a certified high-quality firm $B$ can make profits (the latter inequality is Assumption (A.4)). Here there are two types of PBE in pure strategies. The first class sustains outcome under pessimistic beliefs: No entry occurs. The second class of equilibria sustain outcome under optimistic beliefs: Entry occurs only with high quality, and the incumbent does not reject a high-quality entrant. In addition to the two classes of PBE in pure strategies there may exist a PBE in mixed strategies in which firm $B$ chooses $L$ with a particular positive probability, $\gamma$, and in which the incumbent accepts a low-quality entrant with positive probability, $\varphi$, while it accepts with probability 1 a high-quality entrant (see the Appendix). The set of PBE in mixed strategies in which the entrant enters with probability 1 is either a singleton or empty. It cannot contain more than one element because the belief that a firm is of high quality is uniquely determined, and so are the mixed strategies of the two firms. In Section A.1 of the Appendix, we characterize the candidate mixedstrategy equilibrium in the case that reduced profit functions are linear in expected quality of the entrant. We give conditions for this candidate to be an equilibrium. If the condition that expected profits from entry are nonnegative fails then an equilibrium in mixed strategies does not exist.

An equilibrium which survives the application of the stability criterion by Kohlberg and Mertens (1986) is called KM stable.

Proposition 3. Suppose $\pi_{B}(L)-e<0$. Generically, the set of PBE in pure strategies which supports the outcome with no entry is not KM stable.

The proof is in Section A.2.

We thus have shown that, because a stable set always exists, if the profitability condition for the candidate of a mixed strategy equilibrium is violated, the unique stable set is that of pure strategies equilibria sustaining the outcome under optimistic beliefs. If the profitability condition is strictly met, then also the mixed 
strategy equilibrium constitutes a stable set. ${ }^{18}$ Note that in both cases alliances play a key role in determining the possibility of entry. Both types of equilibria are destroyed if alliances are not allowed.

\section{Extensions}

In this section we briefly discuss some modifications and extensions of the model.

Action Space. Our moral hazard model allowed for 0-1 decisions by the firms $A$ and $B$ which jointly determine whether or not an alliance is formed. If 0 corresponds to stay apart, then the action profiles $(0,1),(1,0)$, and $(0,0)$ imply no alliance. One could consider a different model in which only the action of the established firm $A$ matters; that is, no request by the entrant is required. The argument about the signaling role of the incumbent's action would remain valid. This demonstrates that it is indeed the action of the established firm which solves the asymmetric information problem for the entrant.

Adverse Selection. We obtained our results in an environment of moral hazard. They similarly hold under adverse selection with exogenously given qualities of an entrant. We distinguish two cases.

First, if $\pi_{B}(L)-e<0$, a correctly perceived low quality cannot survive in the market. Then, there exist three classes of PBE: no entry, entry in which only the high-quality firm enters, and pooling equilibria in which both types enter. Depending on the parameters of the model (and Nature's probability distribution of types) the set of pooling equilibria is possibly empty. (For the characterization of the set of pooling equilibria, see the discussion paper version of this paper, Garella and Peitz (2005).) If there are no pooling equilibria with the formation of an alliance we can apply a forward induction argument similar to the intuitive criterion in order to select the set of PBE in which only the potential entrant of high quality enters.

Second, if $\pi_{B}(L)-e \geq 0$, then Assumption (A.3) is violated and a correctly perceived low quality can survive in the market. Then entry of low quality always occurs. We then obtain the signaling role of alliance when consumers recognize their informational role so that the incumbent accepts the entrant if Nature has chosen $H$ and rejects it if Nature has chosen $L$. In such an equilibrium the alliance signals high quality of the entrant. If alliances were not allowed, a high-quality

18. Kohlberg and Mertens (1986) prove the existence of stable sets. Since the set of equilibria sustaining outcome-a (no-entry) is not stable, then the stable set is the one containing all equilibria sustaining outcome-b if no other set of equilibria exist, namely if there is no mixed strategy equilibrium. When the mixed strategy equilibrium exists, we could not find any argument to prune it using KM stability. 
firm would not find it worthwhile to enter, provided that it incurs sufficiently greater fixed costs than a low-quality firm.

Moral Hazard and Adverse Selection-Rejection along the Equilibrium Path. An important concern with respect to the applicability of our model is that in our model with moral hazard alliances are always observed along the equilibrium path. By contrast, in case 2 with adverse selection they are not formed along the equilibrium path. A natural extension can then be analyzed. Consider the case that Nature determines whether or not a firm is capable to produce high quality. That is, a capable firm $B$ decides whether to produce high or low quality and an incapable firm $B$ is always of low quality. Assume furthermore that the cost $e$ depends on whether or not the firm has the capability or know-how. Denote $e_{K}$ the sunk cost for a firm with know-how. Correspondingly, denote $e_{L}$ the sunk cost of firm $B$ that lacks the know-how. Suppose that $\pi_{B}(L)-e_{K}<0$ but $\pi_{B}(L)-e_{L}>0$. Then under the assumptions of our model there exists an equilibrium in which a capable firm $B$ enters with high quality and an alliance is formed, whereas an incapable firm $B$ enters and is rejected by firm $A$. Consumers correctly infer firm $B$ 's quality from the fact that firms have formed an alliance.

\section{Discussion}

In our model the established firm uses its distribution network to distribute its competitor's product. Similarly, it may use its own brand to promote the competitor's product (either as a brand extension or through a co-branding agreement).

The empirical evidence on alliances is in line with the results of our analysis. Recall that in our model the rationale for forming a marketing alliance is the ability of the established firm to convince consumers that the unknown firm produces high quality. This information problem faced by the entrant is likely to be a temporary phenomenon. This suggests that such marketing alliances achieve this goal after a short period of time so that they should be reorganized or possibly taken over by the entrant. Hence, compared to other types of alliances we should expect that marketing alliances are likely to be reorganized or terminated by a take-over. This is indeed the finding of Dussauge, Garrette, and Mitchell (2000) in their analysis of 227 alliances between competitors of which 50 are link alliances that focus on marketing activities. ${ }^{19}$ Furthermore, they find that such marketing alliances are

19. In Tables 2 and 3 of Dussauge, Garrette, and Mitchell (2000) (henceforth DGM(2000)), the authors present regression results for various types of alliances. The variable of interest for our interpretation is called "Link alliances: Marketing" which is one of the explanatory variables for the likelihood of reorganization or take-over of the alliance (or joint venture) in the regressions corresponding to their Table 2 as well as to explain the likelihood of earlier reorganization or takeover in the regressions corresponding to their Table 3. "Link alliances: Marketing" as an explanatory variable for the likelihood of takeovers is significant at the 5\% level. In the other three cases it is 
particularly likely to experience early take-over, which is compatible with our explanation that information can be transmitted into the market.

Our explanation is in particular compatible with the following example. In 1978, the Japanese pharmaceutical company Takeda set up a joint venture with the European chemical and (at that point) pharmaceutical company Hoechst to market one of Takeda's antibiotics (see Dussauge and Garrette 1999, p. 202). Dussauge and Garrette then write

Hoechst ... had little reason to help a new competitor enter a market where it has a strong presence. Only the financial benefits derived from this could justify forming the joint venture with Takeda. Hoechst invested initially very little in the joint venture but, by contributing its marketing know-how, significantly increased the value of the venture and cashed in on this value creation by progressively selling out to Takeda. Hoechst's rationale was that, sooner or later, Takeda would enter the French market and it might as well reap some profits from this entry.

In this example, Hoechst not only provided resources but also was "dealing with local health authorities, local physicians and accessing local distribution networks" (Dussauge and Garrette 1999, p. 202)—this includes Hoechst lending its reputation to Takeda. ${ }^{20}$

Another group of examples can be found in the biotech-pharmaceutical sector. Nicholson, Danzon, and McCullogh (2005) argue that inexperienced biotech companies benefit from an alliance with a pharmaceutical company because it sends a positive signal to prospective investors. Their empirical findings show that biotech companies that sign a deal receive higher valuations from venture capitalists as compared to those that do not sign deals. They also find that biotech companies receive substantially discounted payments when signing their first deals with a pharmaceutical company. This indicates that the latter appropriates part of the gain generated by the alliance as a signal device. ${ }^{21}$

significant at the $1 \%$ level. Note that DGM (2000) offer the complementary explanation for their results that learning effects are initially very important in link alliances. For additional empirical results see Kogut (1991), who, however, does not distinguish between scale and link alliances.

20. In the case of presciption drugs, physicians in ambulatory health care and hospitals, as well as hospital pharmacists, play the role of customers because they generate demand on behalf of the patients. Pharmaceutical companies try to stimulate demand through the use of their own network of medical representatives. Pharmaceutical companies that enter a market can either build up their own network of medical representatives or try to enter through an existing network. Forming an alliance with an established competitior has the advantage not only of avoiding the costly formation of such a network but also of benefiting from the reputation an established company enjoys among its customers (and opinion leaders). Note that reputation is important since the information provided by clinical studies is noisy. We are grateful to Eberhard Wille for providing us with background material on the pharmaceutical industry.

21. Such alliances fit in our framework in those cases where the pharmaceutical company produces drugs that are in competition with the one that shall come out of the biotech project and asymmetric 
Similarly, there are a number of examples in the automobile industry in which the established firm provided market access to products by competing entrants. In several cases this included the sharing of the distribution network, after-sales services provided by the established firm, and in some cases even selling the new product under the established firm's brand name. The management literature refers to such alliances as examples of link alliances where complementary resources are used. ${ }^{22}$ As Dussauge, Garrette, and Mitchell (2004, p. 202) point out, "many link alliances market one partner's products in the other partner's home market." For example, "the 1971 agreements between Chrysler and Mitsubishi, the 1983 NUMMI joint venture between General Motors and Toyota, and the agreements linking General Motors to Isuzu in the 1970s and 1980s, are all examples of link alliances in which a US firm marketed vehicles that its Japanese partner designed."

The importance of alliances with established brands for the brand image of a new brand has been widely recognized in the marketing literature (although the role of competition has not). For instance, Samu, Krishnan, and Smith (1999, p. 57) write "Although advertising alliances can benefit any firm, they are especially important for new brands or established brands entering new markets.... Advertising alliances can be used to achieve brand awareness and brand knowledge goals more effectively by leveraging the strengths of established partners." Although the management literature on alliances has stressed the importance of alliances for market access, it has largely overlooked the information role of such alliances and their effect on competition. An exception is Dowling et al. (1996), who find that alliances between competitors are more likely to be found among larger firms in concentrated industries than among smaller firms in fragmented industries. This is consistent with our theory that reputation sharing becomes viable because of imperfect competition.

Although we have applied our analysis to alliances between competitors, it applies to certain business practices other than alliances. We discuss practices concerning licensing standards, shared retailing space, and exclusionary practices. $^{23}$

information is also relevant for consumers. Our model can be modified to include asymmetric information on the investor side.

22. Broadly speaking, following Hennart (1988) one can distinguish between scale and link alliances. For example, in the automobile industry the former typically involve firms that jointly design or manufacture a car or an important component such as an engine. More generally, many research joint ventures are of this sort, where one firm typically handles design and production and the other provides market access. Other useful references on alliances between competitors include Dussauge and Garrette (1999), Dussauge, Garette, and Mitchell (2000), Garrette and Dussauge (1995), and Hamel, Doz, and Prahalad (1989).

23. The analysis also applies to after-sales services that it provides to the customers of its rival's product. However, shared after-sales services can only be an effective signal if consumers are likely to observe it before making their purchase. For instance, when the product is some specialized machinery for industrial use, the practice of extending firm $A$ 's services of a proprietary repair network to firm $B$ may be readily observed by all users. 
Suppose the incumbent owns rights about the use of a technical standard. When allowed access to the standard the entrant makes a payment to the incumbent. Then, faced with entry, the incumbent may prefer to allow a high-quality entrant access to the standard in return for a license fee, rather than to reject the licensing request. A low-quality entrant will not be able to certify quality and may not be able to survive, so that it will not be allowed to use the standard. Slightly different from the main text, we would argue that maintaining separate standards is costly, so that economies of scope would be present. If these economies are not too strong, our previous argument carries over: In equilibrium, a high-quality entrant obtains the right to use the incumbent's standard whereas a low-quality entrant would not. This serves as a signal to consumers that the entrant is of high quality.

The establishment of shopping malls and trade centers, where sellers must apply for the right to install their facilities, as well as fairs for goods with quality uncertainty can also induce our selection mechanism. Here the idea is that the acceptance or rejection of a particular seller in a shopping mall can work as a signal. ${ }^{24}$ This relies on certain types of shops, for instance those selling men's or women's wear, to be in competition with each other. Side payments can be implicit in the different rental agreements, with low rents for well-established, highly reputed brands. This is consistent with empirical work on rent differentiation in shopping malls (see Pashigian and Gould 1998). ${ }^{25}$ Our paper provides a theoretical argument for rent differentiation which is not based on demand externalities but on asymmetric information of consumers.

Our paper also adds to the current debate on the role of manufacturer brands and private brands. In recent years, Europe and the U.S. experienced an increasing market share of private labels. In addition, in parts of Europe, in particular in Germany and Spain, discounters have played an important role in retailing. These discounters rely primarily on private labels. Margins for private brands have been reported to be the retailers' main profit drivers. Although this suggests a decreasing role of manufacturer brands, they do play an important role in the product offering of most retailers. Interestingly, in Europe, "hard" discounters such as Lidl add brands by leading manufacturers and even Aldi, which used to sell only private brands, has started to sell leading manufacturers' brands. There are multiple explanations about the role of manufacturers' brands. The one related to this paper is that private labels are often compared in quality to national brands. Such a comparison may be seen as more credible if a leading manufacturer brand

24. Through so-called approval clauses a set of established shops control the selection of new shops in a shopping mall. In the 1970s the FTC was concerned about the alleged anti-competitive effect of these approval clauses (see, for instance, Tysons Corner, 85 FTC 970 (1975)).

25. The shopping mall in our set-up only plays the role of offering a selection of goods and thus providing a signaling device. Demand externalities as they often arise in shopping malls are an alternative explanation. 
is offered in the same shelf. The manufacturer may then decide not to lend its reputation to the private label and simply not to offer its product if it considers the quality comparison to be inappropriate. ${ }^{26}$ Although a careful analysis of retailing markets, characterized by buyer power and imperfect competition between retailers, is beyond the scope of this paper we have uncovered an economic mechanism that can be applied to such an environment.

Exclusionary practices such as exclusive dealing, boycotts, and refusals to deal fall much under the same category of actions as analyzed in this paper, provided they are based upon quality of the target. An illustration may be found in the health insurance market in the US, where PPOs can be seen as contractual organizations that select a group of providers of health services among all those which are potentially available. Excluded providers could appeal against exclusion by invoking the boycott or refusal to deal. A defense of PPOs against such lawsuits is that participation to the group is granted according to quality standards. Similarly, hospitals have the right to refuse access to providers of services. ${ }^{27}$

Membership to associations of producers sometimes also performs a role of quality signaling and refused members can file against refusal decisions by the associations. However, if it bases refusal on quality standards, the association is not guilty of hurting competition. Rather, the existence of the association creates an incentive to avoid the moral hazard trap for new producers, as the reputation of members is lent to newcomers. For example, agricultural cooperatives, also engaged in sales and marketing, might need an exclusion mechanism to defend their reputation. Following our model, they do not obtain a competitive advantage from refusing membership to a high-quality entrant, whereas they would do so in the case of a low-quality entrant. ${ }^{28}$

\section{Conclusions}

In this paper, we have shown that an action by an established firm can reveal information about the type of a competitor; information that can be a necessary precondition of the latter's survival. In a game where a firm with an unknown brand has to pay certification costs to convey information about its own product quality, the observable consequences of the rivals' actions can be interpreted by consumers.

26. Note that some retailers offer in addition to an alleged high-quality private brand that matches the leading manufacturer's quality also some basic quality. Our argument applies to the private brand that claims to match the quality of the leading manufacturer's brand.

27. The Federal Trade Commission has recognized that "in some circumstances, contracts where a hospital grants a single firm the exclusive right to perform a particular medical service (e.g., anesthesia) at the hospital can be procompetitive" (Lerner 1984, p. 213).

28. A concrete example is the $\mathrm{VdP}$, an association of German quality wine producers, in which long-established quality wine producers and newcomers coexist. 
The idea that an established firm's action reveals to consumers information about another firm could also have been made precise using an argument available in the context of reputation lending mechanisms (for instance in Biglaiser and Friedman 1994; Chu and Chu 1994). Reputation lending hinges upon what we have called the reputation story: Consumers understand that there is a long-term cost to an established firm, or agent, of loosing its reputation after cheating about the value of a different unknown (new) brand. This cost must be higher than the short-term gain from providing respectability to low-quality firms. Note that the essence of such an argument can apply to different types of interaction between firms and purely relies on consumers punishing the established firm if their beliefs are not confirmed. However, it is questionable whether established firms indeed suffer such a reputation loss.

In our model, the established firm can never lose its reputation. By contrast, we present an argument that relies on product market competition between firms. The established firm, we contend, has an incentive to make consumers believe that the firm with an unknown brand is of low quality. To this end, it can reject to form an alliance with a low-quality entrant to reveal this quality to consumers and improve its relative attractiveness in the eyes of consumers. Provided that a high-quality rival can defend itself by certifying its quality, the rejection of such a rival is not beneficial for the established firm. Even when a firm with certified high quality is not profitable ex ante, the possibility of certification allows a highquality firm to avoid the negative reaction of consumers and thus eliminates the incumbent's incentive to reject high quality. In the extreme, if recognized high quality is a precondition for positive net profits, market structure is changed as the number of competitors is increased compared to an environment in which alliances between competitors are not allowed.

Antitrust authorities have been concerned of the potential anticompetitive consequences of alliances. ${ }^{29}$ However, they have recognized that such alliances can have efficiency-enhancing and pro-competitive effects. Our paper adds to this debate by pointing out a pro-competitive effect due to information asymmetries between firms and consumers. As far as we are aware, this is an aspect that has so far been overlooked.

It would be interesting to extend our formal argument to markets with more than one established firm. Such an extension is, in general, not trivial because it appears that with several established firms an entrant can easily bribe an established firm into an alliance. However, playing one established firm off against another does not necessarily work in a segmented, differentiated product market. In such a market possibly only one of the established is a suitable partner because it offers market access to the most relevant consumer segment. Then our argument about the signaling role of alliances still applies.

29. See, for example, Federal Trade Commission and U.S. Department of Justice (2000). 


\section{Appendix: PBE in Mixed Strategies and Stability}

We consider consumer beliefs with $\operatorname{Prob}\{H \mid(N, 2)\} \in(0,1)$. If $(N, 2)$ obtains in PBE with positive probability, beliefs have to be confirmed. Hence, in any PBE with such beliefs the entrant must be indifferent between choosing $H$ or $L$. Denote the probability that an entrant who is part of an alliance and does not certify is of high quality by $b$, i.e. $b=\operatorname{Prob}\{H \mid(N, 2)\}$. Because a high-quality entrant always certifies when rejected by the incumbent, the incumbent always accepts to form an alliance when facing $H$.

In general, the profits of the firms depend on $b$ in a way which is not linear: $\pi_{A}$ will not be a linear combination of $\pi_{A}(L)$ and $\pi_{A}(H)$. Similarly, $\pi_{B}$ will not be a linear combination of $\pi_{B}(L)$ and $\pi_{B}(H)$. This said, the calculations for a mixed strategy equilibrium can always be done in specific examples where consumers' utility functions, the demand functions, and firms' costs are completely specified. In general there is no presumption that a mixed strategy equilibrium exists.

\section{A.1. Characterization of Equilibrium in Mixed Strategies}

We shall proceed under the simplifying assumption that expected profits are linear combination of the full information profits for both firms. This case only serves for illustrative purposes. ${ }^{30}$ Denote by $\varphi$ the probability of accepting an entrant of type $L$ in the mixed strategy adopted by the incumbent. When faced with $L$ the incumbent's expected profits as a function of $b$ are

$$
E \pi_{A}=\varphi\left(b \pi_{A}(H)+(1-b) \pi_{A}(L)+f\right)+(1-\varphi) \pi_{A}(L) .
$$

For a PBE with mixed strategies to exist it must be $\varphi \in(0,1)$ because if $\varphi=0$, the entrant does not have an interest to produce $L$ whereas if $\varphi=1$ the entrant does not have an interest in producing $H$. For $\varphi$ to be in $(0,1)$, the incumbent must be indifferent between accepting and rejecting an entrant of type $L$. This implies $b \pi_{A}(H)+(1-b) \pi_{A}(L)+f=\pi_{A}(L)$. This equation uniquely determines $b$ :

$$
b=\frac{f}{\pi_{A}(L)-\pi_{A}(H)}
$$

Note that Assumption $\mathrm{A}(1+)$ implies that $b<1$. At stage 1 the entrant has to choose quality. In order to confirm beliefs, the entrant must be indifferent between $H$ and $L$. If she chooses $H$ her profits are

$$
b \pi_{B}(H)+(1-b) \pi_{B}(L)-f-(1-b) h-e
$$

30. Linearity is indeed satisfied if prices are fixed. Also, in a two-sided market context in which "consumers" are not charged for the service but revenues are generated on the other side depending on the number of consumers, we can give specifications such that linearity would be satisfied. 
because an alliance is always formed and with probability $1-b$ the entrant is wrongly perceived to be of low quality. If instead she chooses $L$ then she obtains

$$
\varphi\left[b \pi_{B}(H)+b h+(1-b) \pi_{B}(L)-f\right]+(1-\varphi) \pi_{B}(L)-e .
$$

For the entrant to be indifferent these two expressions must be equal. This reduces to

$$
1-\varphi=\frac{h}{b\left[h+\pi_{B}(H)-\pi_{B}(L)\right]-f} .
$$

Note that when $1-\varphi>1$ the mixed strategy equilibrium does not exist because the incumbent rejects a low-quality entrant with probability equal to 1 . This necessarily happens when $(1-b)(h+f)>b\left[\pi_{B}(H)-\pi_{B}(L)-f\right]$ which is satisfied for the payment $f$ sufficiently small because $b=f /\left(\pi_{A}(L)-\pi_{A}(H)\right)$.

Suppose $1-\varphi>1$. Then a mixed strategy equilibrium exists in the linear specification if the entrant makes positive profits given the calculated probabilities, that is, if

$\frac{f}{\pi_{A}(L)-\pi_{A}(H)} \pi_{B}(H)+\left(1-\frac{f}{\pi_{A}(L)-\pi_{A}(H)}\right)\left(\pi_{B}(L)-h\right)-e-f>0$.

Clearly, this inequality is violated if $f$ is sufficiently small relative to $\pi_{A}(L)-$ $\pi_{A}(H)$.

In a mixed strategy equilibrium equations (A.1) and (A.2) determine $b$ and $\varphi$. Then, let $\gamma$ denote the probability that the entrant choose $L$. A candidate for a quasi-separating PBE has posterior beliefs $b$ satisfying $1-b=\varphi \gamma /[(1-\gamma)+\varphi \gamma]$. This determines $\gamma=(1-b) /(1-b+b \varphi)$.

\section{A.2. Stability-Proof of Proposition 3}

(i) Let $E_{0}$ denote the set of all Bayesian equilibria sustaining the outcome with no entry. When a mixed strategy equilibrium exists and generates positive profits for the entrant the corresponding equilibrium set and the equilibrium set sustaining no-entry, $E_{0}$, are disconnected. Only when a mixed strategy equilibrium exists and generates zero profits for the entrant the corresponding equilibrium set and the equilibrium set sustaining no-entry are connected. The equilibrium set sustaining the outcome under optimistic beliefs is always disconnected.

(ii) Assume that no-entry is a strong best reply for the entrant given the opponent's strategies and the consumers' beliefs. No entry gives zero profits. Then any equilibrium in $E_{0}$ must be formed by beliefs such that $b(N, 1)<1$ to guarantee that an entrant of low quality gets strictly negative expected profits. (Indeed, if one had $b(N, 1)=1$ then a low-quality entrant would get $\pi_{B}(H)-e+$ $h>0$ : from Assumption $\mathrm{A}(3), \pi_{B}(H)-e>0$ because under full information 
a high-quality firm would enter.) Let $\pi_{B}(b)$ denote expected profits from entry with low quality (if expected profits are linear combinations then one can write $\left.\pi_{B}(b)=b\left(\pi_{B}(H)-e-f\right)+(1-b)\left(\pi_{B}(L)-e\right)\right)$. Because no entry is an entrant's strong best reply for the system of belief under consideration, strategy $L$ is not a weak best reply.

A stable set contains all KM stable sets of the game obtained after deletion of any one strategy that is not a weak best reply against the strategy profile adopted by the other players (Proposition 6 in Kohlberg and Mertens (1986)). Then, consider the game $G^{\prime}$ that is the original game except for the deletion of $L$ at the first stage. Clearly, the stable equilibrium sets of this game are such that $H$ is chosen at stage 1 , the incumbent accepts the entrant, and consumers buy according to the belief that both qualities are $H$. The intersection between the set of stable equilibria of $G^{\prime}$ and $E_{0}$ is empty and therefore the set $E_{0}$ cannot contain the stable sets of $G^{\prime}$, so that it is not a stable set of the original game.

(iii) Assume now that no-entry is not a strong but is a weak best reply at the equilibrium under consideration. Then for $L$ to be a weak best reply one should have that the entrant be indifferent between no-entry and $L$ (and $H$ ) in order for the considered equilibrium to belong to $E_{0}$. This means that the incumbent will randomize over accepting and rejecting a low-quality entrant. Hence we are back to our unique mixed strategy equilibrium, with the particular parameter constellation which gives zero expected profits for the entrant. Otherwise the no-entry choice cannot be an equilibrium strategy. Profits equal to zero in the mixed strategy equilibrium corresponds to a set of zero measure in the space of admissible parameter values.

\section{References}

Biglaiser, Gary (1993). "Middlemen as Experts." Rand Journal of Economics, 24, 212-223.

Biglaiser, Gary, and James W. Friedman (1994). "Middlemen as Guarantors of Quality." International Journal of Industrial Organization, 12, 509-533.

Biglaiser, Gary, and James W. Friedman (1999). "Adverse Selection with Competitive Inspection." Journal of Economics and Management Strategy, 8, 1-32.

Bork, Robert H. (1978). The Antitrust Paradox: A Policy at War with Itself. Basic Books.

Brandenburger, Adam, and Barry Nalebuff (1996). Co-opetition. Currency Doubleday.

Carlin, Barbara A., Michael J. Dowling, William D. Roering, John Wymann, John Kalinoglou, and Greg Clyburn (1994). "Sleeping with the Enemy: Doing Business with a Competitor." Business Horizons, September-October, 9-15.

Chu, Woosik, and Wujin Chu (1994). "Signaling Quality by Selling Through a Reputable Retailer: An Example of Renting the Reputation of Another Agent." Marketing Science, 13, 177-189.

Dowling, Michael, William D. Roering, Barbara A. Carlin, and Joette Wisnieski (1996). "Multifaceted Relationships under Coopetition: Description and Theory." Journal of Management Inquiry, 5, 155-167.

Dussauge, Pierre, and Bernard Garrette (1999). Cooperative Strategy. Wiley. 
Dussauge, Pierre, Bernard Garrette, and Will Mitchell (2000). "Learning from Competing Partners: Outcomes and Durations of Scale and Link Alliances in Europe, North American, and Asia." Strategic Management Journal, 21, 99-126.

Dussauge, Pierre, Bernard Garrette, and Will Mitchell (2004). "Asymmetric Performance: The Market Share Impact of Scale and Link Alliances in the Global Auto Industry." Strategic Management Journal, 25, 701-711.

Farrell, Joseph (1986). "Moral Hazard as an Entry Barrier." Rand Journal of Economics, 17, 440-449.

Federal Trade Commission and U.S. Department of Justice (2000). "Antitrust Guidelines for Collaborations among Competitors." April.

Garella, Paolo G., and Martin Peitz (2000). "Intermediation can Replace Certification.” Journal of Economics and Management Strategy, 9, 1-24.

Garella, Paolo G., and Martin Peitz (2005). "Alliances between Competitors and Consumer Information.” International University in Germany Working Paper No. 30/2005.

Garrette, Bernard, and Pierre Dussauge (1995). "Pattern of Strategic Alliances between Rival Firms." Group Decision and Negotiations, 4, 429-452.

Hamel, Gary, Yves L. Doz, and C. K. Prahalad (1989). "Collaborate with Your CompetitorsAnd Win." Harvard Business Review, 67, 133-139.

Hennart, Jean-Francois (1988). "A transaction cost theory of equity joint ventures." Strategic Management Journal, 9, 361-374.

Kogut, Bruce (1991). "Joint Ventures and the Option to Expand and Acquire." Management Science, 37, 19-33.

Kohlberg, Elon, and Jean-Francois Mertens (1986). "On the Strategic Stability of Equilibria." Econometrica, 54, 1003-1038.

Lerner, Arthur N. (1984). "Federal Trade Commission Antitrust Activities in the Health Care Services Field." Antitrust Bulletin, 29, 205-224.

Nicholson, Sean, Patricia M. Danzon, and Jeffrey McCullogh (2005). "Biotech-Pharmaceutical Alliances as a Signal of Asset and Firm Quality.” Journal of Business, 78, 1433-1464.

Ornstein, Stanley I. (1989). "Exclusive Dealing and Antitrust." Antitrust Bulletin, 34, 65-98.

Pashigian, B. Peter, and Eric D. Gould (1998). "Internalizing Externalities: The Pricing of Space in Shopping Malls." Journal of Law and Economics, 41, 115-142.

Samu, Sridhar, H. Shanker Krishnan, and Robert E. Smith (1999). "Using Advertising Alliances for New Product Innovation: Interactions between Product Complementarity and Promotional Strategy." Journal of Marketing, 63, 57-74. 
This article has been cited by:

1. Wolfgang Gick. 2009. Little Firms and Big Patents: A Model of Small-Firm Patent Signaling. Journal of Economics \& Management Strategy 17:4, 913-935. [CrossRef] 